\title{
Phenotypic Characterisation of Escherichia coli Isolates from Fish, Diarrheic and Healthy Children in Zanzibar, Tanzania
}

\author{
A. R. Rabia ${ }^{1}$, P. N. Wambura ${ }^{2}$, S. I. Kimera ${ }^{3}$, R. H. Mdegela ${ }^{3}$, A. Mzula ${ }^{2 *}$ \\ and F. A. Khamis ${ }^{4}$ \\ ${ }^{1}$ Department of Natural Sciences, School of Social and Natural Sciences, State University of \\ Zanzibar, P.O.Box 146, Zanzibar, Tanzania \\ ${ }^{2}$ Department of Microbiology, Parasitology and Immunology, College of Veterinary and Medical \\ Sciences, Sokoine University of Agriculture, P.O.Box 3019, Morogoro, Tanzania. \\ ${ }^{3}$ Department of Veterinary Medicine and Public Health, College of Veterinary and Medical Sciences, \\ Sokoine University of Agriculture, P.O.Box 3021, Morogoro, Tanzania. \\ ${ }^{4}$ Mnazimmoja Hospital, Ministry of Health and Social Affairs, P.O.Box 672, Zanzibar, Tanzania.
}

This was a collaborative work among all authors. Author ARR designed the study, collected specimen from field, carried out and supervised laboratory work, performed statistical analysis and wrote the first draft of the manuscript. Authors PNW, SIK, RMH assisted on study design and in drafting the protocol organizing and refining the manuscript. Author AM played a role on literature citing, organsing and fine tuning of the manuscript according to journal requirements. All authors read and approved the final manuscript.

Article Information

DOI: $10.9734 / / J T D H / 2017 / 34262$

Editor(s):

(1) Ajay Halder, Department of Obstetrics and Gynecology, All India Institute of Medical College, Bhopal, India.

Reviewers:

(1) R. Jasmin, Bishop Heber College, India. (2) Akobi Oliver Adeyemi, Federal Medical Centre, Nigeria. Complete Peer review History: http://www.sciencedomain.org/review-history/20002

Original Research Article

Received $21^{\text {st }}$ May 2017

Accepted $2^{\text {nd }}$ July 2017

Published 11 ${ }^{\text {th }}$ July 2017

\section{ABSTRACT}

Aims: This study was carried out with the objective of investigating $E$. coli virulence factors, antibiotic sensitivity, presence of extended-spectrum- $\beta$-lactamase [ESBL] and serotype H1 O157 in $E$. coli from fish foods in comparison with those from healthy and diarrheic children in Zanzibar. Study Design: Repeated cross sectional design was used to collect samples from fish, vendors 
and fish consumers through the seasons. Cross sectional design was used to collect children faecal samples from Mnazimmoja referral hospital.

Place and Duration of Study: The study was carried out in Zanzibar between August 2014 and June 2016

Methodology: A total of $113 \mathrm{E}$. coli isolates from fish (58), diarrheic (35) and healthy children (20) less than five years old were screened. Serotyping was used for detection of serotype O157 and extended-spectrum- $\beta$-lactamases (ESBL) production by disc diffusion using Cepodoxime/clavulanic acid $(10 / 1 \mu \mathrm{g})$ discs. Hemolysin was detected by hemolysis in human blood agar, serum resistance factors by growth inhibition of $E$. coli that was mixed and incubated with human sera, Hemagglutinins by Hemagglutination of RBCs and Gelatinase enzyme by production of clear zone of degradation of gelatine. Statistical analysis was done using Medcalc statistical software. Statistical difference in virulence factors possession data in $E$. coli isolates between fish, diarrheic and healthy children were subjected to analysis of variance [ANOVA], where $p<0.05$ was judged indicative of significant difference.

Results: Virulence factors detected in their order of prevalence were hemolysins (21.2\%), serum resistance $(12.2 \%)$, hydrophobicity $(8.8 \%)$, Hemagglutinins $(4.4 \%)$, and Gelatinase $(2.7 \%)$. Virulence factors were detected in $82.9 \%$ and $38 \%$ of diarrheic children and fish isolates respectively. E. coli 0157 serotype was detected in all 3 sources with higher percentage in diarrheic children (6.8\%). Extended spectrum $\beta$-lactamase $E$. coli producers were found in fish $(6.8 \%)$ and diarrheic samples (17.1\%) but not from healthy children. Multidrug resistance [MDR] was detected in fish (44.9\%), diarrheic children (82.8\%) and healthy children (10\%). Ampicillin (100\%; $22.4 \%)$ and Tetracycline $(82.9 \% ; 44.8 \%)$ exhibited high antibiotic resistance both in diarrheic children and fish respectively. Fish foods could be sources of pathogenic and antibiotic resistant $E$. coli possessing multiple virulence factors. Moreover 0157 serotypes, ESBL producing and multidrug resistant $E$. coli were also detected in fish foods.

Conclusion: It is therefore emphasised to improve hygiene in the fish value chain as well as raise awareness and frequent monitoring to fish stakeholders in Zanzibar.

Keywords: E. coli; virulence factors; diarrheic children; ESBL; H1 0157.

\section{INTRODUCTION}

The gastrointestinal tract [GIT] of both terrestrial and aquatic animals provide an ideal reservoir habitat of $E$. coli commensals as well as a genetic pool where pathogenic strains could be selected that may ultimately be etiological agents of urinary tract infections [UTI] or other serious systemic infections $[1,2,3,4,5]$. Pathogenic potential of $E$. coli seems to aggravate in immunocompromised individuals [2]. E. coli has also been isolated from environment, vegetables and animal derived foods [6] including marine foods and may be associated with intestinal and extra-intestinal diseases $[7,8,9]$.

Virulence factors in E. coli give them a selective advantage in surviving adverse environmental conditions and ability to overcome the immune system of infected hosts thereby causing inflammation and infection [10,11]. Virulence factors are expressions of virulence genes acquired by horizontal gene transfer carried on plasmids or pathogenicity islands on chromosomes [12]. They may be in the form of cell surface proteins and carbohydrates that mediate attachment and protect the bacteria, bacterial toxins or hydrolytic enzymes. Among $E$. coli virulence factors known to enhance its pathogenicity and virulence are Haemolysins, serum resistance factors, cell surface hydrophobicity factors, Hemagglutinins, enterotoxins, siderophores and fimbriae adhesins. Generally E. coli pathogenic strains are more likely to have higher prevalence of virulence factors and determinants compared to commensals $[13,14,15]$; they also have larger genomes enabling them to encode more virulence factors [16]. On the other hand, some virulence factors may need synergistic presence of other factors to develop disease [1].

Attachment to human cells leading to gut colonisation [17] may be primary in mediating enteric disorders and are related with adhesins on fimbriae F4 (K88), F5 (K99), F6 (987P), F41, and F18 [18]. Hemagglutinins are also known $E$. coli cell surface virulence factors carried by fimbriae. Among important E. coli virulence factors that promote adherence to cells are surface hydrophobicity factors [19]. Possession of a-hemolysins in $E$. coli may be responsible for fatal hemolysis in their hosts [20], serum resistance factors make them resistant to lytic 
action of complement in human sera [10]. Hemagglutinins and hydrophobic factors mediate fimbrial attachment to host cells $[17,21,22]$. $E$. coli related with $\alpha$-hemolysin production are mostly implicated with high pathogenicity and severe urinary tract infections $[23,24,25]$.

E. coli $\mathrm{H} 1 \mathrm{O} 157$ containing shiga toxin is highly pathogenic strain and may be associated with haemolytic uremic syndrome [20].

Production of extended-spectrum- $\beta$-lactamases [ESBLs] that attacks the beta-lactam ring of $\beta$ lactam antibiotics is one of the Enterobacteriaceae resistance mechanisms to counter the action of antibiotics. As of recent, there have been more reports on global increase of resistance on $\beta$-lactam antibiotics [26]. Monitoring the spread of antibiotic resistance among bacteria including $\beta$-lactam antibiotics is important on designing control strategies and curb global spread of antibiotic resistance.

The spread of antibiotic drug resistance among bacteria has raised world concern [27] threatening the ability of the world community to treat common infectious diseases, resulting in prolonged illness, disability, and deaths. Misuse of antibiotics in human practice, animal husbandry systems and agriculture has contributed to a large extent on development of drug resistance. Multidrug resistance, MDR, exhibited by resistance to three or more than three classes of antibiotics [28], is a common phenomenon among Enterobacteriaceae $[29,19]$.

This study was carried out to investigate if fish foods could be potential sources of pathogenic $E$ coli that exhibit virulence factors, ESBLs and $\mathrm{H} 1$ O157 serotype and compare them with E. coli isolates from diarrheic and healthy children. The study also investigated if fish could be potential sources of drug resistance $E$. coli strains in Zanzibar

\section{MATERIALS AND METHODS}

\subsection{Study Area}

The study focused on sixteen popular fish landing sites of Zanzibar islands both Pemba and Unguja. Samples from human subjects were derived from Mnazimmoja referral hospital in Zanzibar town. The sampling sites are spread out in all directions of the two Zanzibar islands Unguja and Pemba - north, south east and west.
Zanzibar is situated in the Indian Ocean between latitudes 4 degrees and 6.5 degrees south of the equator.

\subsection{Research Design}

Repeated cross sectional design was used to collect samples from fish, vendors and fish consumers through the seasons. Cross sectional design was used to collect children faecal samples from Mnazimmoja referral hospital.

\subsection{Sample Collection}

\subsubsection{Sample frame}

Fish samples: Thirteen out of the 207 permanent and makeshift fish landing sites were chosen for sampling to cover all directions of the islands- north, south, east and west of Pemba and Unguja. Sample size was calculated using the formulae

$$
n=\left[\frac{z_{z} /^{\sigma}}{\mathrm{E}}\right]^{2}
$$

The $Z$ value at $95 \%$ confidence interval is 1.96 and the margin of error $E$ is 0.5 .

Fish samples were collected in four seasons; October-December, January-March, April-June and July-September between 2014 and 2015 from three categories- fishers, vendors and consumers; 65 samples were collected from each category each season making a total of 780 samples. Bacteria were isolated and identified by traditional biochemical laboratory methods [31] and MALDI-tof [Matrix-assisted laser desorption/ionization time-of-flight] in Public Health laboratory, Copenhagen. Through proportional sampling, $58 \quad(n=86) E$ coli isolates were randomly chosen for virulence factors determination.

Human samples: Samples from diarrheic and healthy children were collected from Paediatric Unit of the Mnazimmoja Hospital in Zanzibar town between March and June 2016. Samples obtained from diarrheic and healthy children were 35 and 20 respectively.

\subsection{Virulence Factors Detection}

Hemolysin production: a-haemolysin was detected by using plate haemolysis test as 
described by Farrell et al. [32]. The $E$ coli isolates were inoculated onto $5 \%$ sheep blood agar plates incubated for $24 \mathrm{hrs}$ at $35^{\circ} \mathrm{C}$. Clear zones of complete lyses around colonies indicate production of a-haemolysin.

\subsubsection{Serum resistance}

Overnight cultures of the samples grown in nutrient broth were diluted in equal volumes of fresh nutrient broth then incubated for $2 \mathrm{hrs}$ at $37^{\circ} \mathrm{C}$ to give a log phase culture suspension of $10^{5} \mathrm{cfu} / \mathrm{ml}$ [33]. Cells were harvested after centrifugation at $1500 \mathrm{rpm}$ for $5 \mathrm{~min}$ and making suspension in phosphate buffered saline. Equal volumes $(200 \mu \mathrm{L})$ of this suspension and human serum were mixed and incubated in water bath. Ten micro-litres of suspension were withdrawn from samples after 0,120 and 180 minutes and incubated in nutrient agar for plate counting after $24 \mathrm{hrs}$ of incubation at $37^{\circ} \mathrm{C}$. The samples were recorded as serum sensitive or resistant if viable count dropped to $1 \%$ of initial value or if $>90 \%$ of organisms survived after 180 min respectively.

\subsubsection{Cell surface hydrophobicity}

The test was conducted in accordance to Siegfried [34] using salt aggregation test (SAT). Ammonium sulphate solutions with molar concentrations from 0.3125 through $5.0 \mathrm{M}$ were prepared. A loop-ful $\left[\begin{array}{ll}10 & \mu \mathrm{L}\end{array}\right]$ of bacterial suspension in phosphate buffer was mixed with equal volume of ammonium sulphate solution. SAT value was the highest dilution of ammonium sulphate giving visible clumping of bacteria. Aggregation in $0.002 \mathrm{~m}$ phosphate buffer alone [pH 6.8] were considered auto aggregative. $E$. coli strains that had SAT value $\leq 1.25 \mathrm{M}$ were considered hydrophobic.

\subsubsection{Hemagglutination}

A $3 \%$ suspension of human "O" group erythrocytes was prepared by mixing blood with Alservers solution and washing them twice in PBS. One drop of RBCs was then carefully mixed with equal volume of bacterial culture. After 1 minute of rotating the slide observation of macroscopic agglutination was recorded as positive agglutination as in accordance to Vost [35].

\subsubsection{Gelatinase production}

Gelatine agar plates were inoculated with test organisms and incubated overnight at $30 \mathrm{C}$. Gelatinase production was detected by flooding the plates with mercuric chloride solution; the medium was expected to develop opacity while gelatinase producing colonies were expected to have a clear surrounding zone.

\subsubsection{Test for extended spectrum $\beta$ - lactamase (ESBL) production}

Phenotypic confirmatory test was used [36]. Disc diffusion method using Cepodoxime $(10 \mu \mathrm{g})$ and Cepodoxime/clavulanic acid $(10 / 1 \mu g)$ discs was employed. The discs were placed in Mueller Hinton agar plates inoculated with test organisms. After overnight incubation, a difference of $\geq 5 \mathrm{~mm}$ in diameter of zone of inhibition is regarded as positive ESBL production.

\subsubsection{H1:0157 serotyping}

Rapid latex test for detecting non-lactose fermenting $E$. Coli strain $\mathrm{H} 1 \mathrm{O} 157$ was used according to instructions given in the Welcome kit [Microgen, UK]. A drop of latex was placed on three wells of the provided card. Positive control (heat killed antigen, 0157), negative control and cell sunspension of a test organism were placed close to the latex drop and then mixed using separate sticks. Reading was done within 30 seconds and agglutination indicated positive results.

\subsection{Antibiotic Susceptibility Testing}

E. coli samples were sub-cultured in Luria Bertani [LB] Agar [Difco TM 5243817] and incubated at $37^{\circ} \mathrm{C}$ for $24 \mathrm{hrs}$ to obtain pure colonies. The antibiotic susceptibility testing was done using modified Kirby-Bauer disk diffusion method. Pure colonies were inoculated in sterile saline and matched with McFarland standard. The suspension was then spread in Mueller Hinton [Oxoid CM0337] agar plates, antibiotic discs impregnated and, after 24 hrs of incubation, diameters of zone of inhibition was read and interpreted as per CLSI criteria, 2014 [37]. The antibiotics used [Oxoid, England] were Ampicillin [10 $\mu \mathrm{g}]$, Ciprofloxacin [10 $\mu \mathrm{g}]$, Cepodoxime [10 $\mu \mathrm{g}$ ], Gentamycin [10 $\mu \mathrm{g}$ ], Norfloxacin [10 $\mu \mathrm{g}$ ], Nitrofurantoin $\left[\begin{array}{ll}300 & \mu \mathrm{g}\end{array}\right]$, Sulphamethoxoletrimetoprim [25 $\mu \mathrm{g}$ ] and Tetracycline [30 $\mu \mathrm{g}]$.

\subsection{Statistical Analysis}

Statistical analysis was done using Medcalc statistical software. Statistical difference in virulence factors possession data in $E$. coli 
isolates between fish, diarrheic and healthy children were subjected to analysis of variance [ANOVA], where $p<0.05$ was judged indicative of significant difference.

\section{RESULTS}

\subsection{Virulence Factors Detection, 0157 Serotyping and ESBL Production in E coli}

Virulence factor that had highest prevalence were Hemolysin that appeared in $21.2 \%$ (Table 1) of the isolates followed by serum resistance factors exhibited by $12.2 \%$ of the samples. Both virulent factors were detected in fish isolates. Cell surface hydrophobicity was expressed by $8.8 \%$ of the isolates and Hemagglutination of sheep RBCs was at a low level of $4.4 \%$. Lowest number of virulence factor was Gelatinase enzyme production which was seen in $2.7 \%$ of the isolates. Significant difference was observed in virulence factor possession in $E$. coli isolates $(F=5.32, p<0.05)$ between diarrheic and healthy children but not between fish and diarrheic children $[p>0.05]$ demonstrating that virulence factors are comparably high both in fish and diarrheic isolates respectively.

None of the isolates had all five virulent factors. However $22.9 \%$ of $E$. coli isolates recovered from diarrheic children and $10 \%$ from healthy children had two virulent factors. Fish had relatively lower percentage [6.9\%] of isolates with two virulent factors. E.coli with four virulent factors was observed in $3.4 \%$ of fish and $8.6 \%$ of diarrheic children isolates. The overall virulence factor prevalence of $E$.coli isolated recovered from all the three sources was $16.8 \%(19, n=113)$.

Escherichia coli 0157 serotype was detected in $6.8 \%$ of diarrheic and $3.4 \%$ of fish. Extended spectrum $\beta$-lactamase $E$. coli producers were found in fish [6.8\%] and diarrheic samples [17.1\%] but not from healthy children.

\subsection{Antibiotic Susceptibility Findings}

It has been shown that $100 \%$ of isolates from diarrheic children and $55.2 \%$ from fish were resistant to at least one antibiotic compared to $15 \%$ from healthy children. Multidrug resistance [MDR] meaning resistance to three or more than three classes of antibiotics [28] was not detected from any of the isolates. However, all isolates [100\%] from diarrheic children and $22.4 \%$ of isolates from fish are resistant to ampicillin [Table 2]. The next drug that the isolates had higher resistance was tetracycline. Surprising observation was the resistance against Cephodaxime, Ciprofloxacine and Norfloxacine was observed only in fish isolates while low resistance against Nitrofurantoin was observed in fish and healthy children but not in diarrheic children isolates [Table 2].

\section{DISCUSSION}

Virulence factors in $E$. coli are known to confer selective survival advantage and increase their capacity of fitness and cause diseases in affected hosts $[14,38,11,17]$. Suppression of innate immune responses caused by virulence factors is one of important mechanisms that enable pathogenic E. coli to persist within infected hosts [14]. In this study relatively lower overall prevalence of virulence factors $(16.8 \%)$ were detected compared to the finding obtained by rivastava et al. Mittal et al. and Sabitha et al. $[11,19,39]$. This is not surprising because the isolates investigated were from fish foods and gastrointestinal tract; conversely isolates from extra-intestinal infections in most of the cases have higher numbers of virulent factors in concurrence with high pathogenicity as described by Bhrugubalda et al. and Mittal et al. [10,19].

Table 1. Prevalence of virulence factors, 0157 serotype and ESBL production in E coli

\begin{tabular}{|c|c|c|c|c|c|}
\hline $\begin{array}{l}\text { Virulent } \\
\text { Factor/Serotype/ESBL }\end{array}$ & $\begin{array}{l}\text { Fish } \\
n=58(\%)\end{array}$ & $\begin{array}{l}\text { Diarrheic } \\
\text { children } \\
n=35(\%)\end{array}$ & $\begin{array}{l}\text { Healthy } \\
\text { children } \\
n=20(\%)\end{array}$ & $\begin{array}{l}\text { Total } \\
\text { positive } \\
n=113(\%)\end{array}$ & $\begin{array}{l}\text { Statistical } \\
\text { significance } \\
\text { (ANOVA) }\end{array}$ \\
\hline Serum resistance & $6(10.3)$ & $7(20)$ & $1(5)$ & $14(12.2)$ & $\mathrm{F}=5.32$ \\
\hline Hemolysin production & $10(17.2)$ & $12(34.3)$ & $2(10)$ & $24(21.2)$ & \\
\hline $\begin{array}{l}\text { Hemagglutination of } \\
\text { sheep RBCs }\end{array}$ & $1(1.7)$ & $4(11.4)$ & $0(0)$ & $5(4.4)$ & $\begin{array}{l}\text { Fish and } \\
\text { diarrheic }\end{array}$ \\
\hline Gelatinase production & $0(0)$ & $2(5.7)$ & $1(5)$ & $3(2.7)$ & $(p>0.05)$ \\
\hline $\begin{array}{l}\text { Cell surface } \\
\text { hydrophobicity }\end{array}$ & $5(8.6)$ & $4(11.4)$ & $1(5)$ & $10(8.8)$ & Fish and \\
\hline O157 serotype & $2(3.4)$ & $4(6.8)$ & $1(5)$ & $7(6.2)$ & Healthy \\
\hline ESBL production & $4(6.8)$ & $6(17.1)$ & $0(0)$ & $10(8.8)$ & $(p<0.05)$ \\
\hline
\end{tabular}


Table 2. Relative resistance to individual antibiotics

\begin{tabular}{llll}
\hline Antibiotic & \multicolumn{3}{c}{ Source of isolate } \\
\cline { 2 - 4 } & Fish $(\mathbf{n}=\mathbf{5 8})(\mathbf{\%})^{*}$ & $\begin{array}{l}\text { Diarrheic children } \\
\left(\mathbf{n = 3 5 )}(\mathbf{\%})^{*}\right.\end{array}$ & $\begin{array}{l}\text { Healthy children } \\
(\mathbf{n = 2 0})(\%)^{*}\end{array}$ \\
\hline Ampicillin & $13(22.4)$ & $35(100)$ & $3(15)$ \\
Tetracycline & $26(44.8)$ & $29(82.9)$ & $6(30)$ \\
Gentamycin & $5(8.6)$ & $12(34.3)$ & $0(0)$ \\
Cephodaxime & $13(22.4)$ & $0(0)$ & $0(0)$ \\
Ciprofloxacin & $5(8.6)$ & $0(0)$ & $0(0)$ \\
Norfloxacin & $5(8.6)$ & $0(0)$ & $0(0)$ \\
Nitrofurantoin & $6(10.3)$ & $0(0)$ & $2(10)$ \\
\hline \multicolumn{3}{c}{}
\end{tabular}

The higher numbers of Hemolysin $E$ coli producers compared with other resistant factors is a finding to be noted in this study. The overall prevalence Hemolysin $E$ coli producers from fish, diarrheic and health chidren is $21.2 \%$, however in the fish isolates $17.2 \%$ were Hemolysin producers which could potentially be transmitted to humans. Hemolysin production in $E$. coli is mostly associated with more virulent and serious clinical episodes [40,25]. Almost $7 \%$ of fish isolates were ESBL producers. Moreover, Hemolysin production could be linked to high prevalence of ESBL production and drug resistance [40]. Occurrence of high numbers of Hemolysin producers is in consistence with the work of other workers; Bhrugubalda et al. Mittal et al. Mbanga and Mudzana; Sharma and Sabitha et al. $[10,19,29,38,39]$. In this study it is also a noteworthy observation that few isolates from healthy children were also Hemolysin producers $(n=20 ; 10 \%)$.

Hydrophobic virulent factors are among the factors detected in the isolates investigated. The hydrophobic factors are known to mediate attachment to host cells that is primary on pathogenicity and initiating infections [21,41]. Hemagglutinin factors which were also detected in this study are known to mediate cell adhesion and contribute to pathogenicity of $E$. coli [17]. Previous studies have shown that urinary and peritoneal isolates are most hydrophobic [22] suggesting relation of hydrophobicity with pathogenicity.

Serum resistant factors are important virulent factors in resisting the lytic action of complement system present in human sera and their presence may be associated with increased virulence $[10,19]$. More than $12 \%$ of isolates in this study had serum resistance factors with highest occurrence $(20 \%)$ in diarrheic children followed by fish [10.3\%] isolates. Studies on UTI isolates usually have higher prevalence of serum resistance factors than the current study $[10,19,42]$. However, results of this study underline the role of serum factors on pathogenicity and that isolates from fish have potential to cause bacteraemia, UTI and other systemic infections [10].

At least two virulence factors were found in $10.3 \%$ of fish isolates and $31.5 \%$ of diarrheic children while $10 \%$ of isolates from healthy children had two virulence factors. Although human $E$. coli isolates may carry virulence factors without developing disease [1] but generally presence of multi-virulence factors in $E$. coli isolates increase host cell invasion capacity and virulence $[42,43,14]$. Occurrence of lower numbers of virulence factors from healthy individuals compared with diarrheic children is in consistence with other workers who found lower prevalence of virulence factors in commensal E. coli [42]. Moreover occurrence of multivirulence factors in fish isolates cautions that fish could be potential source of pathogenic $E$ coli.

Samples positive for E. coli 0157 serotype were, in this study, obtained from fish, diarrheic children as well as healthy children; $3.4 \%$ of fish isolates were 0157 serotype. Escherichia coli O157:H7, first described from hemorrhagic colitis outbreak [44] is mostly associated with food poisoning epidemics caused by its possession of potent Shiga toxin. Apart from causing diarrhoea, 0157 serotype can also cause haemolytic uremic syndrome [20]. Isolation of this serotype in this study signifies that fish could be a source of E. coli serotypes of public health concern. Moreover previous studies have proved that environment and animal derived foods could be sources of pathogenic $E$. coli to humans $[9,45]$. Furthermore, an issue of public health concern in this study is the isolation of ESBL producing $E$. coli in fish and diarrheic children but not in healthy children. Isolation of ESBL producing $E$. 
coli from fish provides a risk of fish-human transmission [46]. ESBL producing E. coli are also linked with multidrug resistance $[3,10,47,40]$ which is a public health risk. Among factors that favour increase ESBL production is extensive use of antimicrobials [40]. It is cautioned that increased occurrence of ESBL producing Enterobacteriacea is global emerging threat to public health $[48,49]$.

Development of antibiotic resistance among bacteria is a worldwide public health concern that needs concerted efforts by all countries and relevant organisations to curb it down [50]. Prolonged use or misuse of antibiotics ultimately leads to antibiotic resistance [51,52] which could then be transferred to other bacteria through horizontal gene transfer $[53,54,55]$. Similar to Mbanga and Mudzana and Sharma et al. [29,38], this study has also found high resistance against Ampicillin in diarrheic children $(100 \%, n=35)$ than in isolates from fish and heath children. High resistance was also observed in diarrheic isolates against tetracycline-82.9\% $\quad(n=35)$. Resistance found in fish isolates against ampicillin and tetracycline were 22.4 \& and $44.8 \%$ respectively $(n=58)$, however the resistance observed in fish isolates was not as high as in sick children.

It is noteworthy that resistance was found against third generation cephalosporin- Cephodaxime and Cefotaxime from fish isolates. There were isolates from fish resistant to Norfloxacin and Nitrofurantoin. In contrast, no resistance against these drugs was found in diarrheic children. The resistant $E$. coli isolates were most probably derived from poultry owned by fish vendors who are known to be fond of keeping backyard poultry [Veterinary Animal Health and Production Reports, Zanzibar, 2010-2016] [56]. Moreover prescription of these drugs is not very restricted in the Veterinary pharmacies in Zanzibar which thereby encouraging drug resistance and poses a public health risk. It is a point worth noting, however, that these isolates can end up in human food chain. This finding stresses the need to strengthen enforcement of legislation against promiscuity of antibiotic drug use, more so in animal husbandry, for fear of emergence, dissemination and persistence of antimicrobial drug resistance $[51,57,55]$. Moreover results of this study show that fish could play a role on dissemination of drug resistance which again stresses the need to monitor environmental and animal isolates for drug resistance trends lest it should have public health repercussion as was observed by Mellata [51].

\section{CONCLUSION}

Results of this study demonstrate that virulence factors were detected from $E$. coli sourced from all three categories- fish, diarrheic and healthy children with highest prevalence in health children (31.5\%). Serotype 0157 and ESBL producing $E$. coli were also isolated. The results established that fish could be a source of virulent and drug resistant $E$. coli that are of public health importance. There is therefore need to improve hygienic standards in the fish production chain; fishers through vendors to consumers to reduce contamination.

Moreover multiple drug resistance was observed from all three sources and some isolates from fish were resistant to third generation cephalosporins and fluoroquinolones that are drugs of choice for treatment of Enterobacteriaceae infections in humans. This calls for concerted efforts on the part of responsible authorities to regulate and monitor antibiotic drug use in the islands in order to reduce occurrence and ultimate global spread of drug resistance.

\section{CONSENT}

All authors declare that 'written informed consent was obtained from the patient parents on behalf of their children for publication of this paper".

\section{ETHICAL APPROVAL}

All authors hereby declare that all experiments have been examined and approved by the ethics committee Zanzibar Medical Ethics CommitteeZAMREC (PROTOCOL NUMBER: ST/0004/JULY/016) and have therefore been performed in accordance with the ethical standards laid down in the 1964 Declaration of Helsinki.

\section{COMPETING INTERESTS}

Authors have declared that no competing interests exist.

\section{REFERENCES}

1. Cabal A, Castillo M, Cantón R, Gortázar C, Domínguez L, Álvarez J. Prevalence of Escherichia coli virulence genes in patients with diarrhea and a subpopulation of healthy volunteers in Madrid, Spain. Front. Microbiol.2016;7:641. 
Available:http://journal.frontiersin.org/articl e/10.3389/fmicb.2016.00641/full

2. Banu A, iKabin J, Anand, M. Extraintestinal infections due to Escherichia coli: an immerging issue. J Clin Diagn Res. 2016;5:486-490.

Available:http://www.jcdr.net/back issues. asp?issn $=0973709 \times \&$ year $=2011 \&$ month $=J$ une\&volume $=5 \&$ issue $=3 \&$ page $=486$ 490\&id=1331

3. Sharma AR, Bhatta DR, Shrestha J, Banjara MR. Antimicrobial susceptibility pattern of Escherichia coli isolated from urinary tract infected patients attending Bir hospital Nepal. J Sci Tech. 2013;14(1): 177-184.

4. Todar K. Pathogenic E. coli. Online textbook of bacteriology. University of Wisconsin-Madison department of bacteriology. Retrieved 2007-11-30. Uropathogenic Escherichia coli: The preeminent urinary tract infection pathogen. Nova publishers; 2013.

5. Ochman H, Lawrence JG, Groisman EA. Lateral gene transfer and the nature of bacterial innovation. Nature. 2000; (405):299-304.

DOI: $10.1038 / 35012500$

6. CDC Report.

Available:http://www.cdc.gov/ecoli/2016/O 157-02-16/index.html

7. Gazal LE. Puño-Sarmiento JJ, Leonardo PM, Paula SC, Wanderlei DD, Renata KT, Kobayashi GN, Nakazato G. Presence of pathogenicity islands and virulence genes of extra intestinal pathogenic Escherichia coli (Ex PEC) in isolates from avian organic fertilizer. Poult Sci. 2015;94(12).

8. Mary Savin. BCRET members. $E$ coli in flowing waters. BCRET-Big Creek Research and Extension Team.

Available:http://www.bigcreekresearch.org/ docs/Bacteria\%20Trends\%20in\%20Flowin g\%20Waters.pdf.Visited 01.12.2016.

9. Loukiadis E, Kerouredan M, Oswald E, Brugere $H$. Virulence Factors of Enterohemorrhagic Escherichia coli (EHEC) in sewage of french slaughterhouses and environmental risk for public health. Epidemiology. 2006;17(6): \$236.

Available:http://journals.Iww.com/epidem/F ulltext/2006/11001/Virulence Factors of $\mathrm{E}$ nterohemorrhagic Escherichia.608.aspx

10. Bhrugubalda A, Penmetcha U, Yarlagadda $P$, BabuMyeneni R. A Study of virulence factors and drug resistance pattern in
Escherichia coli isolated from extra intestinal infections in a tertiary care teaching hospital, Chinakakani, Guntur, Andhra Pradesh, South India. IJCMAS. 2016;5(4):140-158.

11. Srivastava R, Srivastava $\mathrm{S}$, Agarwal J, Mishra B. Virulence versus fitness determinants in Escherichia coli isolated from asymptomatic bacteriuria in healthy nonpregnant women. Indian. J. Med. Microbiol. 2016;34(1):46-51.

12. Javadi $M$, Oloomi $M$, Bouzari $S$. Genotype cluster analysis in pathogenic Escherichia coli isolates producing different CDT Types. J Path; 2016.

Available:http://dx.doi.org/10.1155/2016/92 37127http://www.hindawi.com/journals/jpat h/2016/9237127/

13. Micenková L, Bosák J, Vrba M, Ševčíková A, Šmajs D. Human extraintestinal pathogenic Escherichia coli strains differ in prevalence of virulence factors, phylogroups, and bacteriocin determinants. BMC Microbiol. 2016;16:218.

14. Waldhuber A, Puthia M, Wieser A, Cirl C, Dürr $S$, Neumann-Pfeifer $S$, Albrecht $S$, Römmler F, Müller T, Zheng Y Schubert S, Groß O, Svanborg C, MiethkeT. Uropathogenic Escherichia coli strain CFT073 disrupts NLRP3 inflammasome activation. J Clin Invest. 2016; 126(7):2425-2436.

DOI: 10 1172/JC181916

15. Bekal S, Vincent A, LinJosee Harel A, Jean-Charles Cote, Cecile Tremblay. A fatal case of necrotizing fasciitis caused by a highly Virulent Escherichia coli strain. Can J Infect Dis Med Microbiol. 2016; ArticleID2796412:4.

Available:https://www.deepdyve.com/lp/hin dawi-publishing-corporation/a-fatal-caseof-necrotizing-fasciitis-caused-by-a-highlyvirulent-uegPPg16CT

16. Rasko DA, Rosovitz MJ, Myers GS, Mongodin EF, Fricke WF, Gajer $P$, Crabtree J, Sebaihia M, Thomson NR, Chaudhuri R, Henderson IR, Sperandio V, Ravel J. The pangenome structure of Escherichia coli: Comparative genomic analysis of $E$. coli commensal and pathogenic isolates. $\mathrm{J}$ Bacteriol. 2008;190:6881-93.

17. Diard M, Garry L, Selva M, Mosser T, Denamur E, Matic I. Pathogenicityassociated islands in extraintestinal pathogenic Escherichia coli are fitness 
elements involved in intestinal colonization. J. Bacteriol. 2010;192:4885-4893.

18. Pereira DA, Vidotto MC, Nascimento KA, dos Santo ACR, Mechler ML, de Oliveira LG Cienc. Rural. Santa Maria. 2016;46(8). Available:http://www.scielo.br/scielo.php?s cript=sci arttext\&pid=S010384782016000 801430

19. Mittal S, Sharma M, Chaudhary U. Study of virulence factors of uropathogenic Escherichia coli and its antibiotic susceptibility pattern. Indian J Pathol Microbiol. 2014;57:61-4.

Available: http://www.ijpmonline.org/text.as p?2014/57/1/61/130899

20. Ferdous M, Zhou K, Mellmann A, Morabito $S$, Croughs PD, De Boer RF. Is shiga toxin-negative Escherichia coli O157:H7 enteropathogenic or enterohemorrhagic Escherichia coli? Comprehensive molecular analysis using whole-genome sequencing. J. Clin. Microbiol. 2015; 53:3530-3538.

DOI: 10.1128/JCM.01899-15

21. Shetty AV, Kumar SH, Shekar M, Shetty AK, Karunasagar I, Karunasagar I. Prevalence of adhesive genes among uropathogenic Escherichia coli strains isolated from patients with urinary tract infection in Mangalore. Indian J Med Microbiol. 2014;32:175-8.

22. Suman E, Gopalkrishna BK, Hegde BM. Bacterial adherence and immune response in recurrent UTI. Int J Gynaecol Obstet. 2001;75:263-8.

23. Jin $Y$, Tang S, Li W, Chien NS, Chan MWY, Sung JJY, Yu J Hemolytic. E. coli promotes colonic tumorigenesis in Females. Canc Res; 2016.

DOI: 10.1158/0008-5472.CAN-15-2083

24. Orf K, Cunnington AJ. Infection-related hemolysis and susceptibility to Gramnegative bacterial co-infection. Front Microbiol;2015.

Available:http://dx.doi.org/10.3389/fmicb.2 $\underline{015.00666}$

25. Slavchev G, Pisareva E, Markova N. Virulence of uropathogenic Escherichia coli. J Cult Collect. 2008-2009;62:3-9.

26. Shaikh S, Fatima J, Shakil S, Mohd S. Rizvi D, Kamal MA. Antibiotic resistance and extended spectrum beta-lactamases: Types, epidemiology and treatment. Saudi J Biol Sci. 2015;22(1):90-101.

Available:https://www.ncbi.nlm.nih.gov/pm c/articles/PMC4281622/\#b0405
27. WHO, 2016 WHO fact sheet. Antimicrobial Resistance; 2016.

28. Awasthi TR, Pant ND, Dahal PR. Prevalence of multidrug resistant bacteria in causing community acquired urinary tract infection among the patients attending outpatient department of Seti Zonal Hospital, Dhangadi, Nepal. Nep J Biotechnology. 2015;3(1):55-9.

29. Mbanga J, Mudzana R. Virulence factors and antibiotic resistance paterns of uropathogenic Escherichia coli. Afr. J. Microbiol. Res. 2014;8(43):3678-3686.

DOI: 10.5897/AJMR2014.7034

30. Six sigma tools and templates, How to determine sample size. Available:http://www.isixsigma.com/toolstemplates/sampling-data/how-determinesample-size-determining-sample-size/. (Accessed on 1/4/2013)

31. Cheesebrough M. Microbiologivcal tests in dsitrict laboratory practice in tropical countries. Part 2. 2 nd edn. New York: Cambridge University Press. 2006;105: 133-136.

32. Farrell DJ, Morrissey I, De rubies D, Robbins, M, Felmingham D. A UK multicentre study of the antimicrobial susceptibility of bacterial pathogens causing urinary tract infection. J. Infect. 2003;46(2):94-100.

33. Raksha $R$, Srinivasa $H$, Macaden RS. Occurrence and characterization of uropathogenic Escherichia coli in urinary tract infections. Indian J Med Microbiol. 2003;21:102-107.

34. Siegfried L, Kmetova M, Puzova $\mathrm{H}$, Molokacova M, Filka J. Virulenceassociated factors in Escherichia coli strains isolated from children with urinary tract infections. J Med Microbiol. 1994; 41:127-132.

DOI: 10.1099/00222615-41-2-127

35. Vosti KL. Relationship of hemagglutination to other biological properties of serologically classified isolates of Escherichia coli. Infect. Immun. 1979;25: 507-512.

36. Bradford PA. Extended spectrum ßlactamases in 21st century: Characterization, epidemiology and detection of this important resistance threat. Clin Microbiol Rev. 2001;933-51.

37. Clinical and laboratory standards institute 950 West Valley Road, Suite 2500 Wayne, PA 19087 USA P: 610.688.0100 F: 610.688.0700 www.clsi.org 
38. Sharma S, Bhat GK, Shenoy S. Virulence factors and drug resistance in Escherichia coli isolated from extraintestinal infections. Indian J Med Microbiol. 2016;25:369-73. DOI: 10.4103/0255-0857.37341

Available:http://www.ijmm.org/text.asp?20 07/25/4/369/37341

39. Sabitha B, Vimal Kumar Karnaker, Geetha RK. Determination of phenotypic expression of the fimbriae and hemolysin of uropathogenic Escherichia coli (UPEC). Int J Adv Med. 2014;1(1):13.pISSN 2349. Available:http://www.ijmedicine.com

40. Shilpa Shenoy, Sumathi K, Veena Shetty A. Comparative evaluation of antimicrobial susceptibility pattern and virulence factors among ESBL and non-ESBL producing $E$ coli. Nitte University. J Health Sci. 2014;4(4).

ISSN: 2249-7110

Available:http://nitte.edu.in/journal/Decemb er\%202014/38.pdf

41. Mulvey MA. Adhesion and entry of uropathogenic Escherichia coli. Cell Microbiol. 2002;4:257.

42. Vaish R, Pradeep M, Setty C, Kandi V. Evaluation of virulence factors and antibiotic sensitivity pattern of Escherichia Coli Isolated from Extraintestinal Infections. Cureus. 2014;8(5):e604.

DOI: $10.7759 /$ cureus.604

43. Emody L, Leremuo M, Nagy G. Virulence factor of uropathogenic Escherichia coli. Int. J. Antimicrob. Agents. 2003;22:29-33.

44. Riley LW, Remis RS, Helgerson SD, McGee HB, Wells JG, Davis RB, Hebert RJ, Olcott ES, Johnson LM, Hargret NTt, Blake PA, Cohen ML. Hemorrhagic colitis associated with a rare Escherichia coli serotype. N Engl J Med. 1983;308(12): 681-685.

45. Sadatsune T, Ramos MC, Nolan LK, da Silveira WD. Overlapped sequence types (STs) and serogroups of avian pathogenic (APEC) and human extra-Intestinal Pathogenic (ExPEC) Escherichia coli Isolated in Brazil. PLoS ONE. 2014;9(8): e105016.

DOI:10.1371/journal.pone.0105016

Available:http://journals.plos.org/plosone/a rticle?id=10.1371/journal.pone.0105016

46. Dahms $\mathrm{C}$, Hübner $\mathrm{NO}$, Kossow $\mathrm{A}$, Mellmann A, Dittmann $K$, Kramer $A$. Occurrence of ESBL-Producing Escherichia coli in livestock and farm workers in Mecklenburg-Western
Pomerania, Germany. PLoS ONE. 2015; 10(11):e0143326.

DOI: 10.1371/journal.pone.0143326

Available:http://dx.doi.org/10.1371/journal. pone.0143326

47. Coque TM, Baquero $F$, Cantón R. Increasing prevalence of ESBL-producing Enterobacteriaceae in Europe. Euro Surveillance. 2008;13:47.

48. Pitout JDD, Laupland KB. Extendedspectrum beta-lactamase-producing Enterobacteriaceae: an emerging publichealth concern. Lancet Infect Dis. 2008; 8:159-66.

DOI: $10.1016 / S 1473-3099(08) 70041-0$

49. Woerther PL, Burdet C, Chachaty E, Andremont $A$. Trends in human fecal carriage of extended-spectrum $\beta$ lactamases in the community: Toward the globalization of CTX-M. Clin Microbiol Rev. 2013;26:744-58.

DOI:10.1128/CMR.00023-13

50. WHO Food safety Fact sheet $N^{\circ} 399$; Dec 2015.

Available:http://www.who.int/mediacentre/f actsheets/fs399/en/

(Visited 10.08.2016)

51. Mellata M. Human and avian extraintestinal pathogenic Escherichia coli: Infections, zoonotic risks, and antibiotic resistance trends. Food. Pathog. Dis. 2013;10:916-932.

52. Stuart B Levy and Bonnie Marshall. Antibacterial resistance worldwide: causes, challenges and responses. Review article. Nat. Med. 2004;10:S122 - S129.

DOI: $10.1038 / \mathrm{nm} 1145$

53. Uchiyama J, Takemura-Uchiyama I, Sakaguchi Y, Gamoh K, Kato S, Daibata M, Ujihara T, Misawa N, Matsuzaki S. Intragenus generalized transduction in Staphylococcus spp. by a novel giant phage. The ISME Journal. 2014; 8(9):1949-52.

DOI: 10.1038/ismej.2014.29

54. Haeusler GM, Curtis N. Non-typhoidal Salmonella in children: Microbiology, epidemiology and treatment. Adv Exp Med Biol. 2013;764:13-26.

Available:https://www.ncbi.nlm.nih.gov/pub $\mathrm{med} / 23654054$

(Visited 10.10.2016)

55. Maluta RP, Logue CM, Casas MRT, Meng T, Guastalli EAL, Rojas TCG, Montelli AC, Sadatsune T, Ramos MC, Nolan LK, da Silveira WD. Overlapped sequence types 
(STs) and serogroups of avian pathogenic (APEC) and human extra-intestinal pathogenic (ExPEC) Escherichia coli Isolated in Brazil. PLoS ONE. 2014;9(8): e105016.

DOI: 10.1371/journal.pone.0105016
56. Veterinary Animal Health and Production Reports, Zanzibar; 2010-2016.

57. Miller LG, Tang AW. Treatment of uncomplicated urinary tract infections in an era of increasing antimicrobial resistance. Mayo Clin. Proc. 2004;79:1048-1054.

(c) 2017 Rabia et al.; This is an Open Access article distributed under the terms of the Creative Commons Attribution License (http://creativecommons.org/licenses/by/4.0), which permits unrestricted use, distribution, and reproduction in any medium, provided the original work is properly cited.

Peer-review history:

The peer review history for this paper can be accessed here: http://sciencedomain.org/review-history/20002 